\title{
Beliefs of grade six learners' regarding adolescent pregnancy and sex
}

\author{
C Grobler, \\ School of Nursing, University of the Free State
}

Y Botma,

School of Nursing, University of the Free State

AC Jacobs,

School of Nursing, University of the Free State

M Nel, Department of Biostatistics, University of the Free State

\section{Correspondence address:}

Rev. Cecilna Grobler

School of Nursing

Faculty of Health Sciences

University of the Free State

PO Box 339,

Bloemfontein

9300

Tel : (051) 4013478

Fax : (051) 4019139

E-mail : groblerc.md( $(\omega)$ mail.uovs.ac.za

\section{Abstract: Curationis 30(1): 32-40}

Escalating adolescent pregnancy and risky sexual behaviour is becoming more common amongst young adolescents and especially amongst black adolescents in South Africa. Statistics confirm that South African adolescents as young as fourteen are already sexually active and become pregnant. The decision to become sexually active with resulting adolescent pregnancy whether planned or not, are directly influenced by the teenager's beliefs. A person's beliefs consist of a person' own individual beliefs or attitude as well as what the individual subjective norm which the individual perceive as other people's beliefs regarding the same object of reason. The aim of the study was to describe the attitude of black grade six learners under the age of fourteen, towards adolescent pregnancy and sex. A quantitative descriptive research design was used. Results were clustered according to demographic variables as well as beliefs that consist of attitude and subjective norm.

Findings provided insight into the beljefs of grade six learners regarding sex and adulthood, the roll of peer pressure, relationships of adolescent parents, social interaction of teenage parents, ability of adolescent parent's ability to provide in the needs of the baby, the adequacy of a child support grant to raise a baby as well as the levels of education of adolescent parents. This article provide a detailed reflection on these results and propose off a doll parenting intervention strategy as means of modification of attitude and subjective norms of grade six learners in order to alter sexual behaviour.

\section{Introduction}

Heightened sexual awareness forms a normal part of adolescent development, yet it is often characterized by experimentation, which has the potential of placing adolescents at risk of unprotected sexual activity, unplanned pregnancy and sexually transmitted infections including HIV infection (American Academy of Child \& Adolescent Pshchiatry, 2004: online). Statistics indicate escalating rates of teenage pregnancy as well as sexual activity at ages as young as thirteen years (The Sensible, Healthy And Responsible People (SHARP) programme n.d.: Online). Literature state that the teenage pregnancy rate amongst black teenage females has increased by almost $33 \%$ over the period 1991-1998, despite a slight decrease of $1.4 \%$ in the national rate over the same period (Pelser 2004:208).

According to Mlangeni (2003: online) girls under the age of sixteen years are 
five times as likely to die during childbirth as women in their twenties. Adolescents - and younger adolescents in particular furthermore have the tendency to give birth to low birth-mass infants who are at risk for neurological and other developmental deficiencies. Due to these high mortality rates amongst adolescent mothers as well as infants, sexual activity amongst adolescents and the resulting adolescent pregnancy has become a primary cause of concern. Adolescent parents are furthermore at a significant disadvantage of becoming a psychosocially and economically contributing adult parent (De Villiers \& Kekesi, n.d.: Online).

Adolescent exposure to the risk of pregnancy has attracted considerable research attention in different societies. Research has indicated that the situation in South Africa resembles that prevailing in developing societies in Africa and Latin America (Mfono, 1998: 180). A literature overview highlighted a number of factors playing a role in the incidence of the high teenage pregnancy rate. Literature state that adolescent's decision to become sexually active and/ or become pregnant are usually influenced by one or more of the following factors:

$\begin{array}{ll}\text { - } & \text { Race and ethnicity; } \\ \text { - } & \text { Poverty, socio-economic } \\ \text { - } & \text { Status; } \\ \text { - } & \text { Lackiosity; } \\ \text { - } & \text { Peer pressure; } \\ \text { Attitudes towards } \\ \text { contraception, condoms and } \\ \text { pregnancy; } \\ \text { Safer-sex behavioural skills } \\ \text { (Elorm, 2003: Online; Mfono, } \\ \text { 1998:180; Kalmuss, Davidson, } \\ \text { Cohall, Larque and Cassell 2003: } \\ \text { Online). }\end{array}$

These factors will have a dual influence on the adolescence as it will influence the adolescent's individual beliefs or attitude as well as those the adolescent perceive as other people's beliefs describe by Ajzen and Fishbein as the learner's subjective norm.

\section{Problem statement}

Statistics confirm that one in every three teenage girls in South Africa falls pregnant before the age of eighteen years (Kalmuss, et al. 2003: Online; Mlangeni 2003: Online; Moagi 2003: online; South
Africa Demographic and Health Survey 1998: Online; Reddy, Panday, Swart, Jinabhai, Amosun, James, Monyeki, Stevens, Morejele, Kambaran, Omardien and van den Borne 2002: 52). Reddy, et. al. (2002: 51-54) state that a significant smaller percentage of "white" learners $(8.5 \%[3.5-13.5])$ reported having made someone pregnant or having been pregnant than black learners $(17 \%[14.1$ 19.8]). It is therefore recommended that "black" and "coloured" learners should especially be targeted through the implementation of programs addressing the problem of adolescent's lenient attitude towards adolescent pregnancy and sex in order to change behaviour.

Sexual behaviour and the resulting adolescent pregnancy is determined by adolescent's attitude toward sex and adolescent pregnancy as well as the adolescent's beliefs that is held by specific individuals or groups with whom he/she stand in relationships. According to the theory of Reasoned Action as postulated by Ajzen and Fishbein in 1980 the intention to perform behaviour is determined by the individual's attitude toward performing a particular behaviour and the subjective norms held by the individual (Shaikh, 2000: Online).

\section{Aim of the study}

The aim of the study was to describe the attitude and subjective norms that form the beliefs that grade six learners have regarding sexual activities and teenage pregnancy. This was done according to the theory of reasoned action as postulated by Ajzen and Fishbein (Shaikh, 2000: Online).

The preliminary objectives of the study was to:

- describe grade six learner's
beliefs regarding sexual
activities and adolescent
pregnancy according to their
individual beliefs as well as
describe grade six learner's
subjective norms regarding
sexual activities and adolescent
pregnancy according to the
person's beliefs that specific
individuals or groups think he/
she should perform specific
behaviours.

\section{Terminology}

The following terminology was used throughout the content of this article:
Adolescent: A young person who has entered puberty but who has not reached full maturity; a teenager. For this study a adolescent is a person aged eleven to thirteen years.

Adolescent pregnancy: Females aged fourteen to nineteen years who are mothers or who have ever been pregnant (South Africa Demographic and Health Survey 1998, 1999: Online).

Grade six learners: Any boy or girl, between ages eleven and thirteen years that attends a primary school at the designated level.

Sexual activity: Any activity involving the touching of genitalia (reproductive organs) of one person by another for the purpose of sexual stimulation including vaginal, oral or anal intercourse (SPAM, n.d.: Online).

\section{Conceptual framework}

The theory of reasoned action as postulated by Ajzen and Fishbein state that behaviour is determined by the individual's attitude and subjective norms (Shaikh, 2000: Online). See Figure 1 for a schematic illustration of the Theory of Reasoned Action.

Attitude is an individual's positive or negative feeling associated with performing a specific behaviour. An individual will hold a favourable attitude toward a given behaviour if he/she believes that the performance of the behaviour will lead to mostly positive outcomes. Should the individual however believe that mostly negative outcomes will result from the behaviour, he/she will hold a negative attitude toward it (Mykytyn \& Harrison, 1993: 1526)

Subjective norms is determined by an individual's normative beliefs that significant people in the individuals life, think he/she should or should not perform a specific behaviour, coupled with motivation to comply with referents. Significant others are individuals whose preferences about a person's behaviour in this domain are important to him/her (Easley \& Chaiken, 1993: Online).

Intention is the likelihood of doing something. An intention is a type of judgment about how, in the present context, an individual will behave toward a particular brand/situation. Intention is the best predictor of behaviour and attitude and subjective norms influence the intention (Shaikh, 2000: Online). 
The individual's beliefs that the behaviour leads to certain outcomes and certain evaluations of these outcomes.

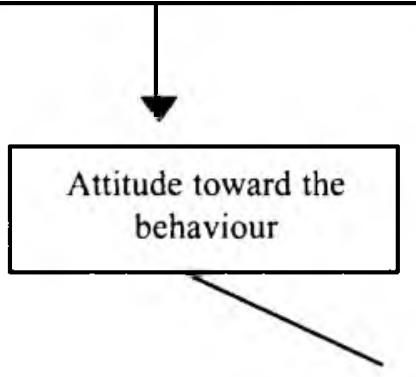

The individual's beliefs that the specific individuals or groups think he/she should or should not perform the behaviour and his/her motivation with the specific referents

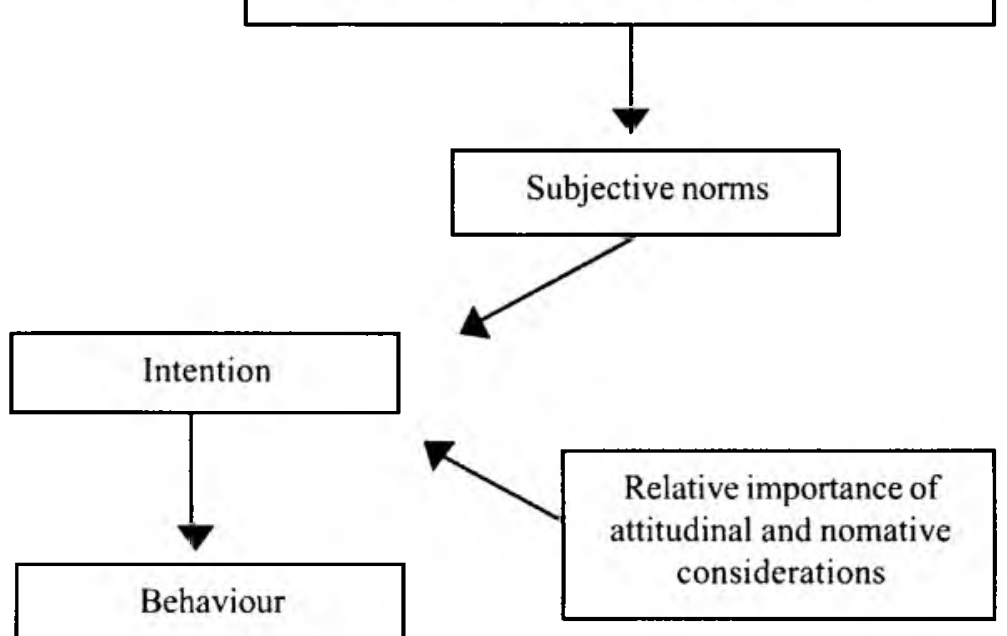

Source : Ajzen and Fishbein (1980)

According to the Theory of Reasoned Action adolescent's attitude and subjective norms will determine the individual's intention towards sexual activity and teenage pregnancy which will thus result in subsequent behaviour. Beliefs that form the attitude as well as subjective norms of grade 6 learners, which will result in intention and subsequent behaviour, had to be determined.

\section{Research methodology}

A quantitative descriptive survey design with a purposive sampling method was used (De Vos, 2002:145-146). A questionnaire was used to determine the beliefs that form the attitude as well as subjective norms towards sexual behaviour and teenage pregnancy.

\section{Research techniques Questionnaire}

According to the Theory of Reasoned Action of Ajzen and Fishbein (1980:2632 ), behaviour is the result of the attitude and subjective norms which will result in intention. Behaviour is a direct result of a specific intention. It was thus necessary to measure the learner's attitude and subjective norms to determine intention and the possible behaviour towards sex. A questionnaire was used with the purpose of defining attitude and subjective norms of the research subjects to determining beliefs or intention regarding sex and sexual behaviour.

In a study of Unger (2000: Online) the Perceived Consequences of Teenage Childbearing (PCTC) scale was used with the objective to describe high school learner's attitude towards teenage pregnancy. The PCTC-scale was however developed for older adolescents and only measured the consequences of adolescent pregnancy and parenting in the United States. A study by Prinsloo (2000:132) used a questionnaire measuring attitude towards sexual activities. Again the instrument was aimed at high school learners

A new questionnaire had to be developed that would be suitable for use with children under the age of thirteen years of age. The School of Nursing of the University of the Free State collaborated with members of the Department of Education, nongovernment organizations, faith-based organizations and community members, in the compilation of the questionnaire. Relevant concepts as identified by means of a thorough study of literature. These concepts, as addressed in the above- mentioned instruments were included in the compilation of the final questionnaire that would determine the beliefs that form the attitude and subjective norms of teenagers towards sexual activities and teenage pregnancy. Literature based questions was used to formulate further relevant questions.

The questionnaire existed of questions addressing the issues of beliefs regarding:

- beliefs regarding sex and adulthood;

- $\quad$ influence of peer pressure in sexual behaviour;

- beliefs regarding personal relationships after having a baby;

- beliefs regarding social interaction after having a baby;

- beliefs regarding ability to provide in the needs of a baby;

- beliefs regarding adequacy of a child support grant to raise a baby;

- beliefs regarding education of adolescent parents.

Two individual translators used a method of back-translation as the questionnaire was firstly translated to Sotho and then back to English. This was done to ensure content validity. The questionnaire was 
thus translated to Sotho as the leamers in this study were grade six learners from a dominantly Sotho-speaking background aged between eleven and thirteen years of age. Back-translation contributed to the reliability of the questionnaire.

\section{Population and sampling}

The population was eighteen traditional black primary schools in Botshabelo using the same life skills programme for grade six learners. The reason for preference of traditional black schools is the fact that the highest prevalence of teenage pregnancy is found under black adolescents (Reddy, et al. 2002: 51 ).

Purposeful selection was used to establish a homogenous group within Botshabelo where the study was conducted. Homogeneity was established on a basis of schools using the same life skills curriculum, schools that have similar numbers of learners, a sinilar socio-economic background from which learners came and age younger than thirteen years. Lack of written consent of parents or legal guardians and absentees on the day of the pre-test was set as exclusion criteria, which left a number of 94 learners included in the study.

Two schools in Botshabelo were purposeful selected for the study. Schools with grade 6 learners in Bothshabelo were listed. The two schools with the largest population of grade 6 leamers under the age of 13 were selected as the experiential and control scools. Only two schools in Botshabelo were selected due to the fact that it was cost as well as time effective. It was decided to use two schools as to be able to generalize findings of the study within a specific area.

When initial selection was done age was not taken into consideration as the average age of a grade six learners is usually cleven years. When the fact that more than fifty percent of grade six learners were older than thirteen years came to the attention of the researchers through data gathered in the pilot study, age was set as exclusion criteria. This was done to ensure that children older than thirteen years, who might already be sexually active, did not influence the results of the study.

\section{Pilot study}

A pilot study is commonly defined as a smaller version of a proposed study conducted to refine the methodology. It is developed much like the proposed study, using similar subjects, the same setting, the same treatment and the same data collection and analysis techniques (Burns \& Grove 2001:49-50).

A pilot study was conducted at a school in Botshabelo, similar to the two schools, which was included into the study. A total of 38 learners were included in the pilot study. The purpose of this pilot study was to determine if the learners understood the questions asked, whether the coding of the questionnaire is correct, and to establish the time necessary to complete the questionnaire. The only adaptation derived from the pilot study was the change of language from English to Sotho, as learners seemed to misinterpret some of the questions.

\section{Data gathering}

The grade 6 learners whose parents gave consent and who gave accent themselves, at both schools on the same date and time completed the questionnaire. Learners included in the study were taken to a separate location in the school where the questionnaire was complcted. Completion of the questionnaire took no longer than 20 minutes at a time. The researchers were present at all times as to answer questions that may derive. The teachers were present to translate any questions of the children as well as the answers of the researchers. The questionnaire was gathered as soon as it was completed.

\section{Data analysis}

Data analysis was done by a biostatistician from the Department Biostatistics, Faculty of Health

Sciences at the University of the Free State. Data was first coded where after it was captured. Data was there after defaulted and processed into frequencies and correlated frequencies. For the purpose of the study the assessment on the questionnaire was summarized as a single group $(\mathrm{N}=94)$. This was done to establish the parameters for the attitude and subjective norms of the group at large.

\section{Results}

The results gathered were clustered according to demographic variables and beliefs of grade six learners regarding sexual activities

\section{Demographic variables}

Demographic variables are characteristics or attributes of the subject that are collected to describe the sample. Demographic variables examined in this study were gender and ethnicity as well as primary caregivers of learners included in the study.

\section{Gender and ethnicity}

The sample ( $\mathrm{N}=94)$ included in the study consisted of more female $(61 \%)$ than male $(39 \%)$ learners in both schools that contributed to homogeneousness of the two groups. These learners come from a mainly Sotho speaking community as indicated by the home languages of learners (See table 1).

The age of the learners ranged between eleven and thirteen years, as age above thirteen years was an exclusion criteria (See Figure 2). When the project was initially planned, the researchers discovered less than $50 \%$ of grade six learners in schools in Botshabelo were under the age of thirteen years with ages ranging up to 18 years. As indicated in Figure 2, 32\% of the learners of the group were already thirteen at the time of the study while the majority of learners $(47 \%$ $(n=44))$ in the group was twelve years of age. In this study none of the learners has ever taken part in sexual activities or had sexual intercourse.

\section{Table 1: Home language of learners}

\begin{tabular}{|l|l|}
\hline Language & Total (n=93) \\
\hline Sotho & 78 \\
Xhosa & 11 \\
Tswana & 5 \\
\hline
\end{tabular}

\section{Primary caregivers}

More than $84 \%$ of all primary caregivers are parents, with grandparents following suite while no sibling households were indicated (See Table 2 ). Out of these primary caregivers, 41 were indicated as female headed households.

Beliefs of grade six learners regarding sexual activities.

Issues addressed in the questionnaire was:

beliefs regarding sex and
adulthood;
influence of peer pressure in


Table 2: Primary caregivers of learners

\begin{tabular}{|l|l|}
\hline Primary caregiver & Total $(\mathbf{n = 9 3})$ \\
\hline Mother and Father & 50 \\
Mother only & 31 \\
Grandmother and Grandfather & 1 \\
Grandmother only & 10 \\
Other family member & 1 \\
\hline
\end{tabular}

sexual behaviour;

- beliefs regarding personal

relationships after having a

baby;

- beliefs regarding social interaction after having a baby; beliefs regarding ability to provide in the needs of a baby; beliefs regarding adequacy of a child support grant to raise a baby;

- beliefs regarding education of adolescent parents.

\section{Discussion}

Cultural background as indicated by language is of importance as literature on studies of sexual behaviour of African students reflects that for a sample of fourteen and fifteen year-olds, between $10 \%$ and $24 \%$ of black girls and $18 \%$ and $62 \%$ of black boys have already had sexual intercourse (Reddy, et.al. 2002:51). The Sensible, Healthy And Responsible

Figure 2: Distribution of age group per school $(N=94)$

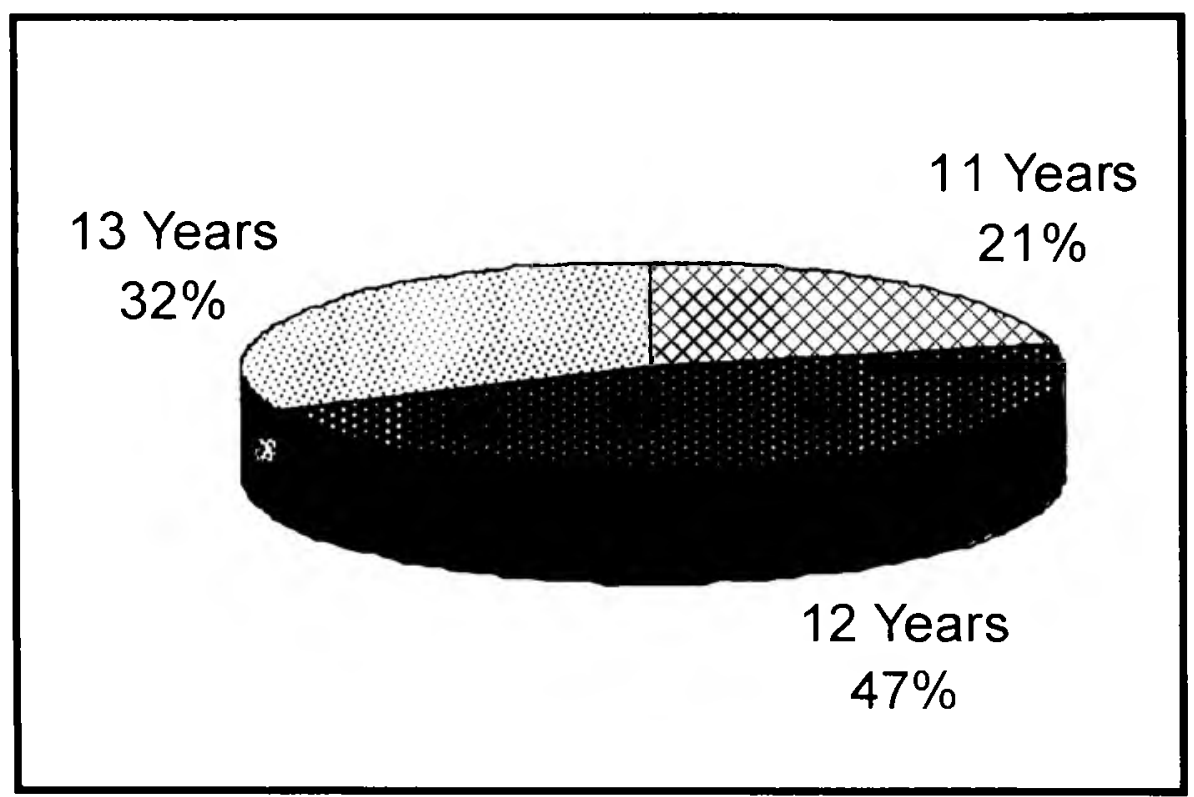
estimated that $75 \%$ of grade ten to twelve learners are sexually active and that $30 \%$ of these learners had an average of three (3) partners and nine (9) sexual encounters in the past year. Reddy, et al (2002: 52) confirms these statistics. The aim of using children under the age of thirteen was to target children of both genders who are not yet sexually active.

Parents being primary caregivers tend to make a difference in the sexual behaviour of adolescents. Kalmuss et al. (2003: Online) state that adolescents who perceive that their mother disapprove of their having sexual activities or who talk with their mother about condom use before first intercourse, are less likely to become sexually active or to fail to use condoms than adolescents whose parents do not communicate with them about sex and sexual activities. Mfono (1998: 182) further state that adolescents in a South Africari study felt that parents just abandoned their responsibility regarding sexual education of their children. In the light of the fact that boys from an African culture tend to become sexually active at a younger age than girls, due to the absence of security and education given by fathers, it is alarming to notice the absence of father figures as primary care givers, as 41 primary
People (SHARP) programme (n.d.: online)

caregivers indicate female headed households (Reddy, et.al. 2002:51). As such, parents play an essential role in the forming of positive subjective norms regarding sexual behaviour and the prevention of teenage pregnancies.

In many black African cultures, children were historically not allowed to discuss sexual activities openly (Ampim 2003: Online). In the olden days however, these children received sex education through the performance of puberty rites. Due to urbanization and industrialization these rites are however seldom performed nowadays. Parents mostly warn adolescents to refrain from sexual activities while the required guidance and discipline is relinquished to overburdened teachers (Elorm, 2003; Sharp, n.d.: Online). Although parents warn adolescents to refrain from sexual activities, adultery, polygamy and promiscuity is often found within the subSaharan cultures (Dahlman \& Jones, n.d.: Online). This behaviour perceived by adolescents as acceptable, lead to adolescents being misguided regarding cultural approved values and moral behaviour.

Another factor that underlie absent parents is the socio-economic status that has a direct influence on the lives of children. The racial and ethnic differences in sexual risk taking and pregnancy are partly attributable to differences in socio-economic disadvantages. According to Elorm (2003: online) children are forced to go into prostitution because it is an easy and fast way of making money for themselves as well as their parents. Adolescents in low income community who have parents with a low educational attainment or are living in a single parent family are also more likely to develop risky sexual behaviours and to fall pregnant at a young age. These adolescent's own level of academic achievement is furthermore positively related to age at sexual debut (Kalmuss, et al. 2003).

According to Ampim (2003) five initiation rites can be distinguished in the African culture, of which one is the rite of adulthood. These rites are usually done at the onset of puberty (around twelve to thirteen years of age in many African cultures) and they are to ensure the shaping of productive, communityorientated responsible adults. The problem however is that mentors of the 


\begin{tabular}{|c|c|c|}
\hline \multirow[t]{2}{*}{ BELJEFS } & \multicolumn{2}{|c|}{$\begin{array}{l}\text { Total } \\
(\mathrm{N}=94)\end{array}$} \\
\hline & Yes $(\%)$ & No $(\%)$ \\
\hline $\begin{array}{l}\text { Beliefs regarding sex and adulthood. } \\
\text { Sex transform a child from childhood to adulthood }(n=92)\end{array}$ & 64 & 36 \\
\hline $\begin{array}{l}\text { Beliefs regarding the influence of peer pressure on sexual behaviour } \\
\text { Acceptance by peers without being sexually active }(\mathrm{N}=94)\end{array}$ & 67 & 33 \\
\hline $\begin{array}{l}\text { Beliefs regarding personal relationships after having a baby. } \\
\text { A baby will strengthen the relationship between the parents of the baby }(\mathrm{N}=94) \\
\text { Boy/girlfriend will raise the baby }(\mathrm{N}=94) \\
\text { Families will raise baby }(\mathrm{N}=94)\end{array}$ & $\begin{array}{l}19 \\
27 \\
36\end{array}$ & $\begin{array}{l}81 \\
73 \\
64\end{array}$ \\
\hline $\begin{array}{l}\text { Beliefs regarding social interaction after having a baby. } \\
\text { Realization of the negative influence adolescent parenting will have on normal } \\
\text { adolescent social interaction }(\mathrm{N}=94)\end{array}$ & 48 & 52 \\
\hline $\begin{array}{l}\text { Beliefs regarding ability to provide in the needs of the baby. } \\
\text { Realization that they would not be able to provide in the needs of a baby }(=73) \\
\text { Realization of the dependency of a child on its parents or primary care giver }(n=38) \\
\text { The baby would really love its parent }(n=91) \\
\text { The baby would really need its parents }(n=91) \\
\text { Teenage parents are able to fulfil all the needs of a baby }(n=92)\end{array}$ & $\begin{array}{l}73 \\
48 \\
54 \\
58 \\
21\end{array}$ & $\begin{array}{l}27 \\
53 \\
46 \\
42 \\
79\end{array}$ \\
\hline $\begin{array}{l}\text { Beliefs regarding the adequacy of a child support grant to raise a baby } \\
\text { Realization that the child support grand is / might be insufficient to raise a baby }(\mathrm{N}=94)\end{array}$ & 61 & 39 \\
\hline $\begin{array}{l}\text { Beliefs regarding education of adolescent parents } \\
\text { Ability to complete school education when having a baby }(\mathrm{N}=94) \\
\text { Adolescents will have enough time for schoolwork while raising a baby }(\mathrm{N}=94)\end{array}$ & $\begin{array}{l}27 \\
17\end{array}$ & $\begin{array}{l}73 \\
83\end{array}$ \\
\hline
\end{tabular}

numerous adulthood "rites of passage"programs have not been initiated themselves with result of askew values being taught to youths, which include values regarding sex and gender rights. Two of the main results of the established beliefs regarding sexual behaviour and gender rights are rape and sexual violence against woman and girls within the communities (Jewkes, Levin \& PennKekana, 2003:127). In a study of Petersen and Bhana $(2003: 28)$ it was found that patriarchal notions of masculinities have a strong influence on rape supportive attitudes.

Literature however state peer pressure as a strong influence on adolescent's sexual behaviour. Peer pressure will influence adolescent's subjective norms as teenagers are at large susceptible of what peers might think they should or should not do. According to Jewkes, Levin \& Penn- Kekana (2003:129-131)) one fifth $(22 \%)$ of sexually active youth say that they have sex with their boy/ girl friend because they are afraid of what their friends will say if they don't. A third $(35 \%)$ of sexually active boys agrees with the statement that it is "cool to have many sexual partners" and attendance of initiation schools is found to be a huge influence in young teenage boys becoming sexually active amongst traditional African cultures. Several studies have highlighted the dominant belief that the more sexual partners a man' boy has, the more he has proven his masculinity. This is an attitude that must be taken into account when promoting the message of being faithful to one partner as an example of safe sex practice (Department of Health, Khomanani campaign 2002:35-38,45).

The presence of a new baby has a definite influence on family life. In a normal marriage, the husband-wife relationship is likely to take a second priority to the ever-present needs of the new infant
(Committee on Adolescence and Committee on Early Childhood, Adoption and Dependent Care 2001:429-434). There are therefore less time for the couple to spend together and feelings of resentment to the new infant may even result due to lack of time for self or spouse. After the birth of an infant, couples have about one third as much time together alone as they had before the birth of the baby (Longo: n.d.: Online).

According to Davies (2005: Online) up to half of the boyfriends and partners are said to be unhappy with their girlfriend's pregnancy. The boyfriends or partners are however much less likely to be negative in their reaction than that of the girls' parents. In the black community, the issue of reparation immediately comes up which is a complicated process which sometimes results in eventual marriage. Young black fathers don't always produce the goods - some studies have found that very few actually pay the full reparation demanded by the girl's 
parents, although most will probably pay something. In western-oriented groups, girls are much less likely to be encouraged to marry the father of their child, and marriage is definitely not the automatic solution that it once was. Yet it also appears that pregnancy in itself is not going to break up all relationships. In Davies' study, nearly $75 \%$ of the girls said that the father of the child was still their current boyfriend.

In pregnancy of an adolescent mother, only $30-50 \%$ of fathers involved are younger than twenty years of age at the time of the child's birth. Therefore there are fewer adolescent fathers than mothers. Adult men who father a child with an adolescent girl tend to be more socio-economically and psychologically similar to adolescent fathers than to adult men who father a child with and adult mother (Young \& D'Archy 2005: Online). Having a baby separates the teenage mother from her former friends, whose interests are now radically different. It is often assumed that this causes resentment and jealousy, making teenage motherhood yet more difficult - but as is so often the case, there is no research to test this assumption. The girls do say that they miss their friends and have a sense of loss with respect to their social life. Giving up your social life is something that all parents must do to some degree, but perhaps this is especially hard for an adolescent (American Academy of Paediatrics: 2001: 429-430).

During the first three to four years of a child have different physical, emotional, educational and communicational needs. During the first three years the anatomic brain structures and physiologic response patterns that determine a child's learning processes, coping skills and personality traits become established, encoded and strengthened. Negative environment conditions, including lack of stimulation or close and affectionate interaction with primary caregivers, child abuse, and violence within the family or even repeated threads of physical and verbal abuse can have a profound influence on these nerves connections and neurotransmitter networks, potentially resulting in impaired brain development.

Since adolescent mothers may not be trained in appropriate stimulation techniques and may be coping with stress in their own lives, ongoing education and support by the paediatrician and other nurturing adults is imperative to help prevent negative sequelae in their offspring. Children of adolescent parents with or without parental involvement, remain a group at risk with a $33 \%$ rate of school dropout, $31 \%$ incidence of depression, $16 \%$ incidence of incarceration and a $25 \%$ risk of adolescent parenthood (American Academy of Paediatrics, 2001:431).

A child support grant in South Africa consists of an amount of R170.00 per child (South African Social Security Agency, 2005: Online). According to Botma and Grobler (2003:36) 11\% of the children included in their study did not have 13 digit birth certificates and $32 \%$ of mothers did not possess a 13-digit identification document of which 19\% themselves was not registered at birth. This indicates the problem that many parents are not able to apply for child support grants. Community members stated the fact that the child support grant is one of the causes that promote adolescent pregnancy, as adolescents coming from a poor background see the amount of the child support grant as sufficient personal income to afford personal luxuries. However, after the babies are born, adolescents seem to realize the fact that the money is barely enough to raise a child, not to speak of personal luxuries.

Van der Merwe (n.d.: Online) supports this by stating that the child support grant has a direct impact on the high incidence of adolescent pregnancies. He further state that these children will not be able to look after their R 170-worth babies and that the next generation will pay the price for the policy regarding the availability of child support grants to adolescent parents.

According to Kaufman, De Wet and Stadler (2000: Online) about $65 \%$ of black girls aged nineteen and younger who had given birth at least once did not complete their school education. According to Shearer (2002:236-243) teenage mothers are likely to experience low educational and occupational achievement and as result live in poverty, as well as have children with behavioural problems, academic difficulties and developmental delays including mild mental retardation. Adolescent fathers are also at risk of school dropout which increases the risk for socioeconomic disadvantage.

\section{Conclusion}

The need of gender awareness programmes such as the Life Skills curricula is therefore strongly indicated to modify such cognitions and create a critical consciousness about these issues of save sexual behaviour and abstinence. The concept of curriculum refers to more than the syllabus and include all planned learning activities and subject courses that take place inside and outside the classroom. According to Carl (2002:35) it is the sum total of the means by which a student is guided in attaining the intellectual and moral requisite of an intellectual citizen. It is further crucial that curriculum planners of the Life Skills program take into consideration issues like social, economic and cultural backgrounds of learners when designing and revising the curriculum.

It is recommended that practical learning experiences such as "doll-parenting" projects be included in the life skills program. Learners of both genders should be exposed to such doll-parenting projects in which a doll is placed into the care of each learner for a period of at least two weeks, twenty four hours a day. Dollparenting expose learners to the necessary responsibility and social impact of having a baby while still an adolescent. A budget-compilation need to be included in the study to accent the financial impacts having a baby will have on adolescent parents and their families.

It is recommended a qualitative methodology should be used for future research as to gain an understanding of the influence of such doll parenting projects on grade six learners' attitude regarding sex and sexual behaviour.

\section{Acknowledgements}

The researchers would like to express appreciation to Ms. Moleme from the Free State, Department of Education who acted as mediator between the Department of Education and the schools involved in the project and who arranged the services rendered by the Free State Department of Education. The researchers would also like to thank Visionary Mentors, Child Line and God bless Africa as well as community members who volunteered to become involved in the project.

\section{References}

AJZEN, I \& FISHBEIN, M 1980: Understanding Attitudes and Predicting Social Behaviour. Englewood Cliffs, NJ: 
Prentice-Hall,Inc.

AMERICAN ACADEMY OF CHILD \& ADOLESCENT PSYCHIARY 2004: Children, Adolescents and HIV/AIDS. $<$ http://www.aacap.org/publications/ factsfam/aids.htm $>$ [Accessed 2003/10/ 28]

AMERICAN ACADEMY OF PEDIATRICS 2001: Committee on Adolescence and Committee on Early Childhood, Adoption and Dependent Care. Care of Acolescent Parents and their Children. Pediatrics. 2001; 107 (2) 429-434.

AMPIM, M 2003. Africana Studies. The Five Major African Initiation Rites. $<$ http://www.manuampim.com/ AfricanInitiationRites.htm> [Accessed 2005/03/24]

BOTMA, Y \& GROBLER, C 2003: Report on participatory situational analysis on household and community practices with regard to health care of children under 5 years in the Motheo district, Free State, South Africa 20022003. Bloemfontein: School of Nursing. University of the Free State.

BURNS, N \& GROVE, SK 2001: The practice of Nursing Research. Conduct, Critique \& Utilization. $4^{\text {th }}$ Edition. WB Saunders Company. Elsevier Science.

CARL, AE 2002: Teacher empowerment through curriculum development into practice. Lansdowne: Juta \& Co.

COMMITTEE ON ADOLESCENCE AND COMMITTEE ON EARLY CHILDHOOD, ADOPTION AND DEPENDENT CARE 2001. Care of Adolescent parents and their children (RE(N)20). Pediatrics 107(2):429-434.

DAHLMAN, J\& JONES, E n.d.: AIDS
in Africa. Www.circumcisioninfo.com/ jones_dahlman.htm> [Accessed 01/08/ 2005]

DAVIES, S 2005. Teenage pregnancy, teenage sex - the South African experience. <http://health.iafrica.com/ $\begin{array}{lllllllllllll}\mathrm{p} & \mathrm{s} & \mathrm{y} & \mathrm{c} & \mathrm{h} & \mathrm{o} & \mathrm{n} & \mathrm{l} & \mathrm{i} & \mathrm{n} & \mathrm{e} & /\end{array}$ articles.teenpregconsequences.htm $>$ [Accessed 14/06/2005]

DEPARTMENT OF HEALTH 2002. Report on the Khomanani Campaign formative and baseline research. $<$ http://
www.aidsinfo.co.za/uploadfiles/PDF/ _Toc 19084717> [Accessed 13/06/2005]

DE VILLIERS, FRP \& KEKESI, J n.d.: Social interaction of Teenage Mothers during and after their pregnancy. <http:/ $/ \mathrm{w} w \mathrm{w}$. c d o c s . c o. z a / modules.php?name $=$ News \& file $=-$ print\&sid-509> [Accessed 18/04/2005].

DE VOS, AS 2002. Research at grass roots. $2^{\text {nd }}$ Edition. Pretoria: Van Schaik

EASLEY, R \& CHAIKEN LE n.d.: Definition of an attitude. <http:// www. business.baylor.edu/ R i c hard_E a s l e y - / / Spring $\% 202000 \% 20 \mathrm{class} / \mathrm{I}>$ [Accessed 24/02/2004].

ELORM KW AME ATISU Teenage southafrica.talkingitglobal.org/express-/ article.html?cid+918> [Accessed 2003/ 10/28]

JEWKES, RK; LEVIN, JB \& PENNKEKANA, LA 2003. Gender inequalities, intimate partner violence and HIV preventive practices: findings of a South African cross-sectional study. Social Science \& Medicine 2003; 56(1): 125-134.

KALMUSS, D; DAVIDSON, A; COHALLA; LARAQUE D \& CASSELL C 2003. Preventing Sexual Risk Behaviours and Pregnancy Among Teenagers: Linking Research and Programs. Perspectives on Sexual and Reproductive Health. $2003 ; 35$ (2): 87 93.

KAUFMAN, CE; DE WET, T\& STADLER, J 2000: Adolescent Pregnancy and Parenthood in South Africa. Policy Research Division Working Paper no. 136. New York: Population Council $<w w w$.popcouncil.org/publications/wp/ $\mathrm{prd} / 136 . \mathrm{html}>$

LONGO, MF n.d.: The impact of Infants on Family Life. <http://ohioline.osu.edu/ hyg-fact/5000.5169.html $>$ [Accessed 24/ 05/2004]

MALLHOTRA, NK 2002: Basic marketing research. Applications to contemporary issues. Upper Saddle River: Prentice Hall. MFONO, Z. 1998. Teenage Contraceptive Needs in Urban South Africa: A case study. International Family Planning Perspectives. 24(4):180-183
MLANGENI, B Pregnancy a Killer of Teenagers, <http://allafrica.com/stories/ 200310130382.html $>$ [Accessed 2003/10/ 28]

MOAGI, M. 2003 Classroom Babies. ht t p ://ww w. sabcnews.com/ specialassignment/babies.html> [Accessed 2003/10/28]

MYKYTYN, PP (JR) \& HARRISON, DA 1993: The Application of the Theory of Reasoned Action to Senior Management and Strategic Information Systems, Information Resources Management Journal, 6(2):15-26.

PELSER, AJ 2004: In Health and Health Care in South Africa. Janse van Rensburg HC. ed. Van Schaik Publishers. Pretoria.

PRINSLOO, SI 2000. Die Seksuele Kennis, Houdings en Gedrag van Senior Primëre Fase Leerlinge in Noordwes Provinsie. Unpublished Minidissertation. PU vir CHO, Potchefstroom.

REDDY, SP; PANDAY, S; SWART, I); JINABHAI, CC; AMOSUN, SL; JAMES, S \& MONYEKI, KD, et al. 2012: Umthenthe Uhlaba Usamila The South African Youth Risk Behaviour Survey 2002. Cape Town: South A frican Medical Research Council 2002. <http:// www.mrc.ac.za/healthpromotion/ healthpromotion.htm > [Accessed 2003/ 10/28]

SA DEMOGRAPHIC \& HEALTH SURVEY 1998: <http://www.mrc.ac.za/ bod/demographicsurvey.h t m > [Accessed 28/10/2003]

SHEARER, DL 2002: Association of early childbearing and low cognitive ability. Perspectives on Sexual and Reproductive Health. 34(5): 236-243.

SHAIKH, Z |n.d.| Review Paper: The theory of Reasoned Action. <http:// www-scf.usc.edu/ zshaikh/HP300Review\%20Paper.pdf'> [Accessed 24/05/ 2004]

SOUTH AFRICANSOCIAL SECURITY AGENCY 2005: You and your grants. <http://www.socdev.gov.za/sassa/ Documents/ugrants.htm> [Accessed: 10/06/2005]

SPOKANE PEER ABSTINANCE MOVEMENT (SPAM) nd: Sexual Definition. <http://www.sd81.k12.wa.us/ 
abstinance/training/definition.htm> [Accessed 24/05/2004]

\section{THE SHARP PROGRAMME} (SENSIBLE, HEALTHY AND RESPONSIBLE PEOPLE) nd: <http:// www.population/org.za/SAPLER/ Pioneers/Proposal/Project\%20Concept/ Projectldentification> [Accessed 24/02/ 2004]

UNGER, AR \& SHAIKH, Z 2000: Review paper: The theory of Reasoned Action. http://www-scf.usc.edu-zxhaikh/ HP300-Review\%20Paper.pdf [Accessed 1/03/2004]

VAN DER MERWE, F 2005: Child support grant is a "disastrous policy" <http://www.zoutnet.co.za/news/ details.asp?StoNum=3206> [Accessed 10/06/2005]

YOUNG, AM \& D'ARCY, H 2005: Older boyfriends of adolescent girls: the cause or a sign of the problem? Journal of Adolescent Health. 2005; 36: 401-419. 